Luciano Parejo Alfonso

Catedrático de Derecho Administrativo

Universidad Carlos III de Madrid

\title{
La potestad de autoorganización de la Adminitración Local
}

SUMARIO: I. INTRODUCCION. LA AUTOORGANIZACION COMO POTESTAD INSTITUCIONAL IMPLICITA EN LA AUTONOMIA LOCAL. II. EL MARCO HETERO. NOMO DE LA ORGANIZACION LOCAL. III. LA AUTOORGANIZACION DE LA ADMINISTRACION LOCAL DIRECTA; EL REGLAMENTO ORGANICO COMO PRINCIPAL MANIFESTACION. IV. LA AUTOORGANIZACION EN EL DOMINIO DE LAS ACTIVIDADES Y LOS SERVICIOS LOCALES; EL PROBLEMA ESENCIAL DE LA LIBERTAD DE ELECCION DE LAS FORMAS ORGANIZATIVAS. V. LA AU. TOORGANIZACION EN EL AMBITO DE LAS RELACIONES INTERADMINISTRATIVAS.

\section{INTRODUCCION. LA AUTOORGANIZACION COMO POTESTAD INSTITUCIONAL IMPLICITA EN LA AUTONOMIA LOCAL}

Resumiendo su propia doctrina, el Tribunal Constitucional, en su Sentencia 170/1989, de 19 de octubre (fundamento jurídico 9), señala que la autonomía local, tal y como se reconoce en los artículos 137 y $140 \mathrm{CE}$ goza de una garantía institucional con un contenido mínimo que el legislador debe respetar (STC 84/1982). Esa garantía institucional supone el derecho de la Comunidad Local a participar a través de órganos propios en el gobierno y la administración de cuantos asuntos le atañan, graduándose la intensidad de esta participación en función de la relación existente entre los intereses locales y los supralocales en el contexto de tales asuntos o materias. Para el ejercicio de esa participación en el gobierno y la administración en cuanto les atañe, los ór- 
ganos representativos de la Comunidad Local ban de estar dotados de las potestades sin las que ninguna actuación autonómica es posible (STC 32/1981, fundamento jurídico 2). Más allá de este límite de contenido mínimo que protege la garantía institucional, la autonomía local es un concepto jurídico de contenido legal, que permite, por tanto, configuraciones legales diversas, válidas en cuanto respeten aquella garantía institucional.

La autonomía local constitucionalmente garantizada supone, pues, una organización propia de la correspondiente Comunidad, a través de la que se ejercita justamente el derecho de participación en los asuntos públicos en que consiste, incluso en su configuración legal ordinaria y conforme al artículo 2.1 de la Ley $7 / 1985$, de 2 de abril, reguladora de las bases del régimen local. Justamente por ello los artículos 140 y $141 \mathrm{CE}$ confieren personalidad jurídica a Municipios y Provincias y prefiguran - fundamentalmente por relación al principio de representatividad - su respectivo sistema de gobierno y administración. La autonomía local o, mejor, las autonomías locales expresamente contempladas por la norma fundamental son, pues, poderes públicos (en cuanto forman parte, según el art. $137 \mathrm{CE}$, de la organización territorial del Estado, en calidad - a tenor de la denominación del Capítulo II del Título VIII del propio texto constitucional- de Administraciones) y ordenamientos territoriales dotados de personalidad jurídica independiente.

El concepto cualitativo de autonomía que consagra, así, la Constitución pone en primer término la dimensión organizativa, pues con la garantía de dicha autonomía de lo que se trata es de asegurar la existencia y el funcionamiento de centros de decisión dotados de una economía y una lógica propias, cifradas en el principio de la gestión de los correspondientes intereses bajo la propia responsabilidad ${ }^{1}$.

Este tipo de gestión (autónoma) administrativa presupone por sí misma, como antes se ha visto que entiende la doctrina del Tribunal Constitucional, la dotación de la organización que la personaliza con las potestades institucionales propias de todo poder administrativo territorial y sin las cuales éste no podría operar como tal y conforme a su lógica propia.

Por de pronto, la referencia constitucional de la autonomía (art. 137 CE) a la gestión de los respectivos intereses, presupone en las corres-

1 Así resulta de la doctrina sentada por el Tribunal Constitucional en las Sentencias previamente citadas en el texto; doctrina, resumida en la STC 170/1989, de 19 de octubre. Por su parte, el Tribunal Supremo así lo tiene establecido también, siguiendo al Tribunal Constitucional.

Véanse las SSTS de 5 de actubre de 1983 (véase en la obra de M. DE LOPE y L. SANZ FER. NANDEZ: Administración Local y Constitución. Jurisprudencia del Tribunal Constitucional y del Tribunal Supremo, Ed. IEAL - hoy INAP-, Madrid, 1986, vol. I, p. 322, Cdo. 2."), 17 de febrero de 1987 (en la misma obra, vol. III, p. 235, Cdo. 5.') y 25 de enero de 1988 (Ar. 357, Cdo. 2." de la sentencia apelada; véase también en la obra antes citada, vol. III, pp. 563 y ss.). 
pondientes organizaciones locales la doble capacidad (potestad) de decidir tanto normativamente (dictar normas con rango y valor de Reglamentos), como mediante resoluciones de supuestos concretos (dictar actos administrativos) ${ }^{2}$. Pero está implícita en ella también la potestad de autoorganización ${ }^{3}$, es decir, el poder de determinar y con-

2 En el fundamento jurídico sexto de su Sentencia 214/1989, de 21 de diciembre, sobre la Ley 7/1985, de 2 de abril, reguladora de las Bases del Régimen Local, el Tribunal Constitucional señala, en efecto que: «... en lo concerniente a la organización municipal, el orden constitucional de distribución de competencias se funda en el reconocimiento de tres ámbitos normativos correspondientes a la legislación básica del Estado (art. 149.1.18 de la Constitución), la legislación de desarrollo de las Comunidades Autónomas según los respectivos Estatutos y la potestad reglamentaria de los Municipios, inherente esta última a la autonomia que la Constitución garantiza en su articulo 140\%. En este punto, la jurisprudencia del Tribunal Supremo, uniforme y constante, data ya por lo menos de 1981 y declara con claridad que en la autonomía consagrada en el artículo 137 CE está implícita la potestad normativa. En este sentido, SSTS de 4 de diciembre de 1981; 1 de marzo, 21 de junio y 18 de octubre de 1983; 3 de marzo y 30 de octubre de 1984; 27 de marzo de 1985; 18 de marzo de 1986; 13 de julio de 1987 y 29 de septiembre de 1988 (las seis primeras en vol. I, las tres siguientes en vol. II y las dos últimas en vol. III de la obra citada en la nota núm. 1, respectivamente pp. y Cdos.: 189, 2."; 259 y ss., 3."; 304 y ss., $6 .^{\circ}$ y $7 .^{\circ} ; 326$ y $327,3 . .^{\circ} ; 370$ y ss., $4 . .^{\circ} ; 199$ y ss., $3 .^{\circ} ; 245$ y ss., $2.0 ; 446$ y ss., $6 .^{\circ}, 419$ y ss., $6 .^{\circ}$ de la apelada, y 940 y ss., 3.\%). Respecto a las dos últimas Sentencias, también Ar. 6893, 7280 , respectivamente.

3 En este sentido, la STS de 18 de julio de 1988 (Ar. 5908, Cdo. 2. de la Sentencia apelada) señala que la autonomía local, tal como se encuentra institucionalmente garantizada en los artículos 137 y $140 \mathrm{CE}$, exige la concreción de un ámbito de competencias propio de los Ayuntamientos, junto con un poder de autoorganización y el reconocimiento de una específica potestad normativa. Por su parte, la STS de 8 de abril de 1987 (Ar. 4251, Cdo. 1. ${ }^{\circ}$ ) apunta que dentro del haz de potestades de las Corporaciones Locales se encuentra la de autoorganización, lo que permite a dichas Corporaciones crear los órganos que consideren adecuados para el mejor funcionamiento de los servicios y el cumplimiento de sus fines propios. Y la STS de 20 de mayo de 1988 (Ar. 4194, Cdo. 1.9) alude, a propósito de la necesidad de cohonestar el régimen local general o común con la especificidad de cada ente local autónomo, al reconocimiento implícito de competencias a los entes locales de competencia para ordenar aquellas cuestiones en que tengan peculiaridades y, muy especialmente, en la de autoorganización y funcionamiento propio. Ya con anterioridad, la STS de 18 de junio de 1986 (véase en la obra citada en la nota anterior, vol. II, pp. 520 y ss., Cdo. $\left.4 .^{\circ}\right)$ habia indicado, sobre la base de la directa aplicabilidad de las disposiciones organizativas constitucionales (concretamente las contenidas en su Título VIII), la titularidad en los Municipios de una potestad para regular la organización y el funcionamiento de sus órganos de gobierno en el marco del ordenamiento.

La doctrina científica coincide mayoritariamente a ese respecto con la jurisprudencia indicada. Véase, si bien con referencia a la autonomía de las Comunidades Autónomas, J. L. CARRO FERNÁNDEZ-VALMAYOR: «Sobre la potestad autonómica de autoorganización», REDA, núm. 71, p. 322 (el trabajo, con algunas variantes, ha sido publicado también en la obra colectiva, dirigida por dicho autor, Comentarios al Estatuto de Autonomia de Galicia, Ed. INAP, Madrid, 1922), para quien la competencia en materia de organización administrativa es una competencia implicita en la autonomía garantizada constitucionalmente, que no necesita, por ello, expreso apoyo normativo y que tiene, naturalmente, carácter instrumental respecto de las competencias sustan. tivas asumidas por las Comunidades Autónomas en sus respectivos Estatutos de Autonomía. Véanse también las otras coincidentes opiniones doctrinales, que dicho autor recoge $y$, concretamente las de F. SOSA WAGNer-CABALlERo, en la obra colectiva Comentarios al Estatuto de Autonomia de la Comunidad Autónoma del Principado de Asturias (dirigida por R. Bocanegra Sierra), Ed. MAP-IEAL, Madrid, 1987, pp. 83 y 84; CARRERAS SERRA: «Organització de les institucions d'autogovern», en la obra colectiva Comentaris sabre l'Estatut d'autonomia de Catalunya, Ed. Institut d'Estudis Autonòmics, Barcelona, 1988, vol. I, p. 393; M. BASsols ComA: «Los órganos ejecutivos de las Comunidades Autónomas: Presidencia y Consejo de Gobierno", REDA, núms. 40/41, p. 106. 
figurar su estructura de gobierno y administración, tanto directa, como indirecta o instrumental, así como también el de articular la intervención local en la vida económica y el de codeterminar - junto con otras Administraciones - las estructuras derivadas de la cooperación en el ámbito de las tareas comunes a, o compartidas por, todas ellas. Es por ello plenamente consecuente con el concepto de autonomía local asumido constitucionalmente la opción de la Ley $7 / 1985$, de 2 de abril, reguladora de las bases del régimen local (en adelante LRBRL), consistente, de un lado, en la regulación separada de las potestades institucionales de los entes locales necesarios y territoriales (Municipio, Provincia e Isla) y las competencias sustantivas y sectoriales de los mismos, y, de otro lado, en la inclusión entre las primeras (art. 4.1) de la expresada potestad de autoorganización, junto con la reglamentaria y las de programación y planificación, entre otras.

Inmediatamente ha de precisarse que esta potestad de autoorganización no es plena, ha de moverse dentro de un amplio pero preciso marco constitucional y legal ordinario.

\section{EL MARCO HETERONOMO DE LA ORGANIZACION LOCAL}

En cuanto la organización traduce o articula la forma en que se produce el autogobierno aludido por el principio de autonomía, la Constitución se ocupa —en sus arts. 140 y 141 - de los aspectos más relevantes de la misma. A tenor de tales preceptos, en efecto, el autogobierno local ha de ser:

- Democrático, en el sentido de ser realizado bien directamente por los propios ciudadanos (Concejo abierto), bien por representantes de éstos, elegidos tanto directamente (desde luego los Municipios), como indirectamente (las Diputaciones y los Cabildos y Consejos Insulares); de donde resulta la estrecha conexión del gobierno y la administración locales con el derecho fundamental a la participación en los asuntos públicos consagrado en el artículo 23 del texto constitucional ${ }^{4}$.

No puede dejar de mencionarse aquí que, tras la ratificación por España de la Carta Europea de la Administración Local y su incorporación, por tanto, al Derecho interno en calidad de Ley estatal, la potestad de autoorganización -en tanto que contenido necesario de la autonomía local- cuenta con el apoyo suplementario de su prescripción por el artículo 6.1 de dicha Carta en términos ciertamente amplios. A tenor del aludido precepto, las Entidades Locales deben -como mínimo y sin perjuicio de una previsión legal más generosa- poder definir por sí mismas las estructuras administrativas internas con las que pretenden dotarse, con objeto de adaptarlas a sus necesidades específicas.

4 La STS de 25 de enero de 1988 (Ar. 357, Cdo. 3.०) destaca, con ocasión de la determinación del contenido de la autonomía local, la relación de la misma con el derecho consagrado en el artículo $23 \mathrm{CE}$. 
- Personificado, lo que indica que es expresión de ordenamientos parciales y limitados, pero completos en sí mismos y, por tanto, no jerarquizados en sentido estricto y riguroso al gobierno de ninguna otra de las instancias territoriales; quiere decirse, pues, que el gobierno local lo es, como ya nos consta, bajo la propia responsabilidad dentro del marco acotado por la ley, de suerte que, si bien no excluye técnicas de articulación con los poderes superiores (dirección, coordinación, control) para asegurar la efectividad del referido marco legal, requiere que tales técnicas no lo coloquen en una posición genérica de subordinación o dependencia, incluso causi jerárquica; y

- Articulado sobre el principio corporativo (corporaciones primarias, en el caso de los Municipios, y secundarias, en el de las Provincias y las restantes agrupaciones municipales que puedan crearse; sin determinación precisa, sin embargo, en el caso de las Islas), estando llamado, por ello, a gestionar el universo de los intereses de la comunidad respectiva, lo que significa su dotación con los atributos correspondientes a las Administraciones territoriales. $Y$ con precisión, para los Municipios, de la estructura del sistema de gobierno: el Ayuntamiento, integrado por el Alcalde y los Concejales (predeterminándose implícitamente su desglose en dos órganos básicos, al fijar taxativamente el régimen de elección de los segundos y permitir, sin embargo, un doble sistema - directo e indirecto- para la elección del primero).

Consecuentemente, la autonomía local es - desde la perspectiva constitucional ahora adoptada - un tipo de Administración Pública determinado por las notas expuestas, que se resumen en el autogobierno o la autoadministración democráticos (directos o representativos) bajo la propia responsabilidad, dotado de una organización en correspondencia con tales notas y definida en sus principios fundamentales por la misma norma constitucional.

En la medida en que el gobierno local es así, por decisión directa constitucional, entera y únicamente Administración, es claro que las organización de las Administraciones locales -incluida la derivada de decisiones adoptadas por estas últimas en ejercicio de su respectiva potestad de autoorganización- pertenece al ámbito acotado por la norma fundamental (art. 149.1.18) con la expresión «régimen jurídico de las Administraciones públicas»; materia, en efecto, en la que - a tenor de las Sentencias del Tribunal Constitucional 32/1981, de 28 de julio, y $76 / 1983$, de 5 de agosto- tiene una amplitud mayor que la evocada por el procedimiento y los recursos, incluyendo también la regulación de la organización de todas las Administraciones públicas. Quiere esto

La estrecha relación comentada luce en la propia LRBRL, siquiera por lo que hace a la instancia municipal. Al definir ésta, el artículo 1.1 la caracteriza por ser cauce inmediato de participación ciudadana en los asuntos públicos. 
decir que, estando distribuida la competencia legislativa en tal materia conforme al binomio bases-desarrollo, es claro que la potestad de autoorganización local tiene como marco último, en cualquier caso, el régimen jurídico básico que para todas las Administraciones públicas establezca el Estado y, en el contexto del mismo, el determinado específicamente para los entes locales por la legislación básica del régimen local ${ }^{5}$.

La LRBRL, sin perjuicio de atribuir a los entes locales necesarios (justamente los previstos expresamente en los arts. 140 y 141 de la Constitución) la potestad de autoorganización (art. 4.1), desarrolla las reglas principales constitucionales, concretando, así, el marco en el que aquélla ha de ejercerse, en los siguientes términos:

\section{A) Municipios}

Reiterando el dato de la personificación de su gobierno y administración, confiere expresamente a la Entidad capacidad jurídica plena para el cumplimiento de sus fines (art. 11.1). De modo conforme con el principio corporativo, establece los elementos estructurales del Municipio de los tres clásicos de las corporaciones territoriales: el territorio (el término dentro del que la Entidad ejerce sus competencias), la población (el conjunto de los residentes en el término) y la organización (arts. 11.2 y 12).

En punto a organización, tras la reiteración de la regulación constitucional y la remisión a la legislación general electoral de los aspectos de este último carácter (art. 19), dispone:

\section{Estructura organizativa ${ }^{6}$ :}

1.1. Una serie de reglas, basadas en la distinción entre órganos necesarios y complementarios, que deben ser respetadas por cualquier ulterior medida organizativa?.

5 En este sentido, no puede perderse de vista que el desarrollo ordinario del estatuto constitucional de la Administración pública como un todo está aún pendiente. Justamente cuando se escriben estas líneas parece puesto en marcha, a iniciativa del Gobierno, el proceso legislativo que ha de conducir al establecimiento del nuevo régimen jurídico básico de las Administraciones Públicas, una vez abandonado al parecer y al menos por ahora, el propósito de enmarcar dicho régimen una previa Ley del Gobierno. Obvio resulta decir, que la futura Ley básica en esta materia definirá un marco en el que habrá de situar el concreto régimen jurídico de los entes locales ya definido por la Ley $7 / 1985$, de 2 de abril.

6 Se adopta en la exposición un concepto estricto o reducido de la organización, por lo que no se alude en la misma a los medios materiales (comprendidos los económico-financieros) y los personales.

7 Estas reglas se contienen en el articulo 20 y se refieren, en lo que ahora interesa, a los órganos necesarios, bien en todos los Municipios sin excepción (Alcalde, Tenientes de Alcalde y Pleno; se entiende a salvo la excepción constituida por el régimen de Concejo abierto), bien sólo en los de determinada población mínima (Comisión de Gobierno). 
1.2. La doble condición de órgano unipersonal ejecutivo y Presidente de la Corporación (y, consecuentemente, del Pleno) del Alcalde y la lista de sus competencias (art. 21).

1.3. La composición del Pleno y sus competencias (art. 22).

1.4. La composición de la Comisión de Gobierno y su definición como órgano colegiado de asistencia y apoyo al Alcalde, capaz sólo de ostentar competencias propias únicamente por expresa atribución por una Ley sectorial o, en otro caso, a simple título de delegación por parte de otros órganos municipales (art. 23.1 y 2).

1.5. La determinación de los Tenientes de Alcalde como órganos unipersonales y, además y en su caso (allí donde exista), miembros de la Comisión de Gobierno, con el doble carácter de sustitutos (por su orden) de:l Alcalde y de destinatarios de delegaciones por parte de éste (art. 23.3 y 4).

1.6. La habilitación para el establecimiento de órganos territoriales de gestión desconcentrada (con la organización, funciones y competencias que cada Ayuntamiento les confiera), sin perjuicio de la unidad de gobierno y gestión del Municipio (art. 24).

1.7. La configuración del espacio competencial municipal (arts. 25 a 28 ).

1.8. La previsión de régimenes municipales especiales: el de los Concejos abiertos (art. 29) y los establecidos por la Ley autonómica para Muricipios pequeños o de características peculiares, en el marco de la legislación estatal básica (art. 30).

\section{Funcionamiento:}

2.1. Un conjunto de reglas bajo la expresiva rúbrica de «régimen de funcionamiento» (Capítulo I del Título V, arts. 46 a 54).

2.2. La regulación de las relaciones de los entes locales con las otras Administraciones Públicas (Capítulo II del Título V, arts. 55 a 68).

2.3. La ordenación básica de la información a los ciudadanos y la participación de los mismos (Capítulo III del Título V, arts. 69 a 72).

2.4. La determinación de las formas de gestión de los servicios públicos locales y del ejercicio de actividades económicas (arts. 85 y 86).

\section{B) Provincias e ISLAS ${ }^{8}$}

Tras reiteración, idéntica a la que opera en el caso de los Municipios, de las determinaciones constitucionales (naturaleza de agrupación de Municipios, personalidad jurídica, gobierno por Diputaciones u

8 La extensión a las Islas de las prescripciones legales relativas a las Diputaciones trae cau- 
otras Corporaciones representativas), consagración aquí también de la plena capacidad de obrar (art. 31.1 y 3). De modo consecuente con la naturaleza de estas unidades, falta toda referencia a los elementos territorial y poblacional (aunque el primero viene predeterminado constitucionalmente -art. 141.1, inciso final-, no deja de ser la suma de los términos de los Municipios agrupados), centrándose la regulación legal en el de la organización. A este respecto dispone:

1. Estructura organizativa:

1.1. Guardando paralelismo con la regulación relativa a los $\mathrm{Mu}$ nicipios, una serie de reglas de necesario respeto por cualquier ulterior media organizativa, apoyadas en la diferenciación entre órganos necesarios y complementarios (art. 32).

1.2. Determinación de la composición del Pleno y de sus competencias (art. 33).

1.3. Fijación de las competencias del Presidente de la Corporación, con el resultado de su doble configuración como órgano unipersonal ejecutivo y Presidente del órgano colegiado representativo máximo de aquélla (art. 34).

1.4. Prefiguración de la Comisión de Gobierno como órgano colegiado de asistencia y apoyo al Presidente y recipiendario de delegaciones por parte de los restantes órganos corporativos (así como titular de competencias propias únicamente por atribución expresa de Leyes sectoriales), con precisión de su composición, así como de los Vicepresidentes como órganos unipersonales de la confianza del Presidente, de sustitución, por su orden, de éste y destinatarios posibles de delegaciones del Presidente (art. 35).

1.5. Delimitación del espacio competencial provincial (arts. 36, 37 y 38 ).

1.6. La previsión de regímenes especiales (Comunidades Autónomas uniprovinciales, Comunidad Foral de Navarra y órganos forales de Alava, Guipúzcoa y Vizcaya) (arts. 39 y 40).

2. Funcionamiento: Las mismas determinaciones que en el caso de los Municipios, por ser comunes a ambos tipos de entes locales.

La potestad de autoorganización juega, pues, en el marco prefijado por las prescripciones legales apuntadas (a las que deben añadirse las autonómicas dictadas en desarrollo de la legislación básica, que aquí, por obvias razones, no es posible detenerse a estudiar). Esta potestad está reconocida en todo caso con carácter muy amplio. El artículo 4 LRBRL la enumera, junto con la potestad reglamentaria, entre las que

sa de lo prevenido en el artículo 41.1 para los Cabildos insulares y en el artículo 41.3 para los Consejos insulares. 
se atribuyen desde luego a los entes locales territoriales y los artículos 20.2 (para los Municipios) y 32.2 (para las Provincias e Islas) —en la versión resultante de la STC 214/1989- contemplan los Reglamentos Orgánicos de cada uno de dichos entes locales como normas propias para la determinación -en el marco de la organización necesaria fijada por la LRBRL y la normativa de desarrollo establecida por las Leyes de Régimen Local de las correspondientes Comunidades Autónomasde la organización específica de los mismos. Y, finalmente, los artículos 7.3 (en relación con la regulación de la delegación de competencias en los entes locales y las facultades de dirección y control que se puede reservar la Administración delegante) y 59 (en relación con la coordinación de la actividad de los entes locales mediante planes) se cuidan de salvar siempre la potestad de autoorganización, en el primer caso, y el ejercicio de las facultades de programación, planificación u ordenación de los servicios o actividades de su competencia en el marco de aquellos planes por parte de los referidos entes locales. Finalmente, la regulación de las formas de gestión de los servicios públicos locales (art. 85) es muy flexible y permite amplias posibilidades de configuración a los entes locales.

En términos más concretos, el estatuto de la capacidad de decisión local dirigida a la propia organización presenta en la LRBRL los perfiles siguientes:

a) La autoorganización constituye la expresión más genuina, el núcleo mismo de la autonomía local, como resulta sin duda alguna de lo dispuesto en los artículos 20.2 y 32.2 y de las reservas y salvedades que, en su favor, efectúan los artículos 7.3 in fine y 62, párrafo segundo, todos ellos de la LRBRL. Esta concepción de la autoorganización es plenamente conforme con la Carta Europea de la Administración local, cuyo artículo 6.1 impone a la legislación interna de los Estados un contenido mínimo a este respecto, concretamente el acotado por relación al poder de definición de las estructuras administrativas internas para su adaptación a las necesidades específicas locales.

b) La potestad normativa correspondiente, en cuanto referida a la organización de los entes locales, tiene un marco legal único y preciso: la legislación de régimen local, tal como resulta del artículo 5.a) LRBRL (afirmación que debe tenerse por correcta, con entera independencia de que este precepto, como veremos, haya sido declarado inconstitucional por razones puramente formales). Esta característica es consecuencia de la propia delimitación y configuración de la materia «régimen local» efectuada por la LRBRL y declarada conforme a la Constitución por la STC 214/1989, de 21 de diciembre.

c) La LRBRL (art. 5, en relación con los arts. 20.2 y 32.2), sobre la base de la combinación de los dos elementos anteriores, define directamente el marco legal y el contenido-alcance de la potestad nor- 
mativa de autoorganización, de suerte que - a este respecto- lo básico, al identificarse con el mínimo unitario de autonomía, hace superfluo cualquier desarrollo (ésta es la razón de la posición ordinamental secundaria de la Ley autonómica en este concreto punto).

Ocurre, sin embargo, que el estatuto así sintetizado no ha resistido con éxito, en todas sus partes y facetas el examen de constitucionalidad verificado por el Tribunal Constitucional en su Sentencia 214/1989, de 21 de diciembre. Dos son los elementos del mismo que han sido objeto de una crítica adversa, con resultado de declaración de su inconstitucionalidad: el sistema de fuentes consagrado en el artículo 5 LRBRL, que está en la base misma de aquel estatuto, y el contenido, alcance y posición en el ordenamiento de los entes locales de los Reglamentos Orgánicos por estos dictados. Ninguno de estos dos juicios de (in)constitucionalidad de la LRBRL son plenamente convincentes; antes al contrario, suscitan serios reparos.

Dejando el examen de las consideraciones del Tribunal referidas a la reglamentación orgánica para cuando estudiemos esta figura, es claro que el artículo 5 LRBRL ha sido valorado por el Tribunal Constitucional a la luz de su propia doctrina sobre la ilegitimidad de las normas legales ordinarias (del poder legislativo constituido) meramente interpretativas de la Constitución, es decir, cuyo objeto se agote en una tal interpretación: doctrina, que había sentado por primera vez en su Sentencia 76/1983, de 5 de agosto, sobre el proyecto de Ley Orgánica y de Armonización del Proceso Autonómico. Ocurre, sin embargo y con independencia de la opinión que se pueda tener sobre la corrección de la doctrina en cuestión, que entre los supuestos enjuiciados en uno y otro caso no se da la identidad mínima precisa para justificar semejante aplicación. Es lógico, por ello, que el Tribunal haya debido pagar por ella el precio de incurrir en una clara contradicción interna en el conjunto de sus razonamientos sobre la LRBRL. En efecto:

- Sobre el artículo 5 mismo, el fallo del Tribunal Constitucional argumenta en dos niveles.

Primero sienta la naturaleza interpretativa del precepto: «En cuanto que enumera las normas aplicables en una materia en la que la competencia legislativa está dividida entre el Estado y las Comunidades Autónomas, el precepto ha de ser entendido, en consecuencia, como una norma interpretativa de lo dispuesto en el bloque de la constitucionalidad respecto de esta materia.»

Inmediatamente pasa a extraer la conclusión: «Es esta naturaleza de norma meramente interpretativa, sin contenido material alguno, la que hace el precepto constitucionalmente ilegítimo. El orden de fuentes en un ordenamiento compuesto es el establecido por el bloque de constitucionalidad, sin que uno de los elementos de esta realidad com- 
puesta, en este caso el legislador estatal, pueda imponer a todos los demás, como única interpretación posible, la que él mismo hace.» - La base en la que descansa por entero la conclusión de inconstitucionalidad es más que discutible. Por de pronto, no es fácilmente justificable la introducción en el razonamiento (sin precisión, además, de su eficacia en la economía del mismo) de la idea consistente en que la Ley opera en una materia en la que la competencia legislativa está dividida entre el Estado y las Comunidades Autónomas. Esta división es algo nada inusual en el sistema constitucional de distribución territorial de competencias y ocurre en todos los supuestos articulados sobre la distinción bases-desarrollo, sin que de tal circunstancia resulte que en ellos el legislador estatal básico quede mermado, limitado o de cualquier otra forma condicionado en su capacidad de configuración de la regulación que, en cada materia, le corresponda en lo que efectivamente sea básico. Quiere decirse, pues, que del hecho de la división o el reparto de la competencia legislativa en la materia entre el Estado y las Comunidades Autónomas no deriva sin más y necesariamente que toda la regulación básica del Estado deba ser susceptible de desarrollo por normas legales autonómicas (que es lo que quiere decir el Tribunal Constitucional, olvidándose de sus propias soluciones, radicalmente distintas, en otras ocasiones, sobre todo en la materia de la ordenación de la economía); antes bien, semejante afirmación, para ser válida, habría requerido una suficiente justificación de por qué una cuestión básica - consistente en la acabada delimitación del marco legal de la autonomía local, que, por su propia naturaleza, no es susceptible de desarrollo- ha de precisar constitucionalmente, no obstante, tal desarrollo legislativo autonómico.

- Yendo al meollo de la cuestión, la incursión por una norma en el supuesto de mera interpretación requiere, como es obvio (y explicita el propio Tribunal Constitucional, que equipara la norma «meramente interpretativa» a la «sin contenido material»), que su contenido dispositivo no forme parte, de manera necesaria o justificable, de la regulación sustantiva de la materia constitutiva del soporte y, al propio tiempo, del objeto del título competencial ejercitado, es decir, no sea verdadero y legítimo (competencialmente) «desarrollo» de la norma constitucional. En otras palabras, la afirmación del carácter simplemente interpretativo del artículo 5 LRBRL habría requerido una fundamentación de la concurrencia de tal supuesto, ya que, en otro caso, habría sido obligado -incluso con la misma rotundidad- el pronunciamiento efectuado por el propio Tribunal en su Sentencia 227/1988, de 29 de noviembre, al rechazar paralela imputación con relación a la Ley de Aguas:

«Una cosa - dijo entonces dicho Tribunal (fundamento jurídico 3) - es que el legislador estatal realice, con pretensiones normativas 
de validez general, una interpretación genérica y abstracta del sistema constitucional y estatutario de distribución de competencias, subrogándose en el ejercicio del poder constituyente sin una expresa previsión constitucional o estatutaria (supuesto contemplado en la STC 76/1983, de 5 de agosto, en la que los recurrentes se apoyan), y otra muy distinta que ejerza las potestades normativas que la Constitución y los Estatutos de Autonomia le atribuyen especificamente para la regulación de un sector material del ordenamiento. El desarrollo de esta actividad requiere, como presupuesto lógico, una interpretación del alcance y los límites de la competencia legislativa del Estado, definida en la Constitución y en los Estatutos. Semejante operación interpretativa, que es común al ejercicio de toda potestad pública, no está vedada, sino que resulta imprescindible en el iter de elaboración de toda norma o acto de los poderes públicos, pero que no puede confundirse con el resultado concreto a que se llegue en cada caso. Si en la regulación de una determinada materia el legislador ba desbordado o no los límites establecidos en la Constitución y en los Estatutos de Autonomía, es cuestión que atañe al correcto o incorrecto desempeño de los poderes que le ban sido conferidos por el constituyente, los cuales, por amplios o genéricos que puedan ser en algunos casos, no suponen ejercicio del poder constituyente mismo, estando sujetos en todo caso al control de constitucionalidad de las leyes que la Constitución encomienda a este Tribunal como su intérprete supremo.»

Lejos de proporcionar, cumplidamente, la aludida fundamentación, el Tribunal Constitucional se limita —en el caso que nos ocupa- a indicar, con carácter genérico, que el orden de fuentes en un ordenamiento compuesto como el español no puede quedar entregado a la disposición de uno de los poderes territoriales constituidos. Con esta principal aseveración no es posible, en modo alguno, discrepar. Pero la cuestión no es tan sencilla, pues ni es cierto que la LRBRL pretendía establecer el orden de las fuentes en el ordenamiento español en su conjunto, ni parece correcta la negación tan tajante de que el desarrollo constitucional no cubra legítimamente la definición del orden de las fuentes de algunos de los ordenamientos autónomos reconocidos, amparados y sostenidos por aquel ordenamiento general $(y$, entre ellos, el ordenamiento local, en cuanto ordenamiento en el marco de la Ley formal ordinaria y objeto el mismo de una de las materias con las que opera el sistema constitucional de distribución de competencias); el objeto en este punto de la LRBRL es mucho más modesto: determinar la estructura de uno (el menor, por meramente administrativo, como queda dicho) de los ordenamientos territoriales de aquel ordenamiento global del Estado compuesto, lo cual es radicalmente distinto y afecta a un ordenamiento respecto del cual -y por diferencia 
a los de las Comunidades Autónomas- parece preciso reconocer ${ }^{9}$ la legitimidad de su prácticamente entera definición en sede infraconstitucional (por estar fuera de su disposición la construcción legal de sí mismo y corresponder constitucionalmente, según contradictoriamente reconoce el propio Tribunal Constitucional, al Estado en el sentido de poder central). En la medida en que, según dicho Tribunal (en el fundamento jurídico núm. 1 de la propia sentencia analizada y con invocación de la doctrina ya sentada en la anterior Sentencia 32/1981, de 21 de julio, y reiterada en las Sentencias 76/1983, de 5 de agosto, y 27/1987, de 27 de febrero), la competencia ex artículo 149.1.18 CE supone una acción normativa reflexiva del Estado, conectada en este caso nada menos que con la garantía institucional de la autonomía local, no es posible negar que la determinación del sistema de fuentes del ordenamiento local, en tanto que subordenamiento autónomo de alcance exclusivamente administrativo (definido precisamente por el marco acotado por la Ley), es una determinación necesaria e inherente a la aludida competencia y a una determinación constructiva necesaria por razón de las características peculiares del objeto mismo de dicha competencia: la definición de un ordenamiento, y en ningún caso, por tanto, simple o meramente interpretativa, es decir, genérica, abstracta y dotada de una pretensión de validez general. Resulta inconsecuente, en efecto, tal negación, cuando la misma Sentencia había previamente determinado - desestimando uno de los motivos aducidos en los recursos de inconstitucionalidad acumulados- el contenido de la materia constitucional «régimen local», reconociendo la peculiaridad -en el sentido indicado- de la misma, al decir textualmente: «El régimen local, que es, por tanto, el "régimen jurídico de las Administraciones Locales", resulta de este modo no una materia evanescente, disgregada en una pluralidad de asuntos sometidos a un régimen competencial diversificado, tal como afirma la Generalidad de Cataluña, sino una materia con perfiles propios que, por imperativo de la garantía institucional de la autonomia local, contempla también - y no excluye- lo relativo a las competencias de los entes locales.» Más consecuente con esta última argumentación que la opinión de la mayoría determinante del fallo es la opinión disidente plasmada en el voto particular formulado por el Magistrado don Eugenio Díaz Eimil.

9 Incluso por exigencia de la propia doctrina sentada por el Tribunal Constitucional a propósito de la autonomía local. Véase, por todas, la STC 170/1989, de 19 de octubre, fundamento jurídico 9. 


\section{LA AUTOORGANIZACION DE LA ADMINISTRACION LOCAL DIRECTA; EL REGLAMENTO ORGANICO COMO PRINCIPAL MANIFESTACION}

Como no podía ser de otra forma, dada la conexión existente entre los preceptos, la argumentación desarrollada y la conclusión alcanzada por el Tribunal Constitucional con ocasión del examen artículo 5, A) LRBRL le condicionan totalmente a la hora del análisis de los artículos 20.2 y 32.2 del texto legal. Consecuente aquí con su posición, ya criticada, de que la materia «régimen local» presupone, desde el punto de vista legislativo, tres ámbitos normativos superpuestos por el siguiente orden: legislación básica estatal, legislación de desarrollo autonómico y reglamentación (orgánica) local, reinterpreta los preceptos legales de que ahora se trata en el sentido de que el marco legal, límite de la potestad normativa propia de los entes locales para su autoorganización, no viene constituido sólo por la Ley básica, sino también por la correspondiente Ley autonómica de desarrollo de ésta. El resultado es que, quedando suprimido el carácter secundario en este punto de la legislación autonómica, el ámbito reservado a la autoorganización local queda indeterminado, por referido, en expresión del propio Tribunal, a aquel espacio no precisado que «... no podrá ser desconocido o invadido por las normas que, en materia de organización municipal complementaria, dicten las Comunidades Autónomas». No parece que así quede precisamente bien servida la autonomía local, ni desarrolla$\mathrm{da}$, en términos constitucionalmente aceptables, la garantía institucional de que la misma goza. Tanto más, cuanto que parece más que plausible estimar que la solución así establecida no cumple satisfactoriamente las exigencias mínimas dirigidas a la legislación estatal por el artículo 6.1 de la Carta Europea de la Administración local (medida de referencia ésta curiosamente no tenida en cuenta por el Tribunal Constitucional, a pesar de que la ratificación por España de la Carta data de 20 de enero de 1988 y la firma de mucho antes). La consideración de esta Carta habría determinado muy probablemente un pronunciamiento distinto del Tribunal Constitucional, toda vez que le habría situado en otra y más correcta perspectiva (la que luce, cabalmente, en el voto particular a la opinión mayoritaria plasmada en la Sentencia), a saber, la del contenido mínimo común de la potestad de autoorganización a asegurar en todo caso a todos los entes locales necesarios, en tanto que componente dicha potestad del núcleo mismo de la autonomía local. Téngase en cuenta, en efecto, que uno de los efectos más negativos de la solución adoptada por el Tribunal Constitucional y capaz, por ello, de desacreditar ésta por sí solo, es el de la posibilidad que abre a configuraciones distintas — según la densidad que im- 
prima a la propia regulación de desarrollo de la legislación básica cada Comunidad Autónoma - del espacio propio de la reglamentación orgánica local.

Tras la Sentencia 214/1989, de 21 de diciembre, pues, si bien aparece reafirmada la potestad normativa local de autoorganización (incluso en su origen y fundamento constitucionales), no por ello deja de experimentar una rebaja o dilución, de dudosa corrección, tanto en su posición ordinamental (que resulta «normalizada» por relación a los restantes aspectos o extremos del Régimen Local), como en su ámbito o espacio propio, entregado éste —en su última definición- a la voluntad del legislador autonómico (pues fácilmente puede comprenderse la dificultad de su defensa jurídica por las Corporaciones Locales caso a caso).

La cuestión central que plantea el Reglamento Orgánico como instrumento para la organización de la Administración propia es, sin embargo, la de la extensión y el alcance de su objeto legítimo. A tenor de las previsiones de la LRBRL éste es amplio y permite un despliegue suficiente de la capacidad organizativa local, pues autorizan desde luego a que el Reglamento Orgánico ${ }^{10}$ aborde:

a) La ultimación, en el nivel de detalle, del estatuto de los miembros de la correspondiente Corporación, naturalmente en el marco del bloque de la legalidad integrado por la LRBRL y la legislación autonómica de desarrollo. El campo no es pequeño, si se piensa - aparte cuestiones adjetivas, como la de los tratamientos honoríficos- en la solución de problemas tales como el registro de intereses de los miembros electos o la constitución, el funcionamiento y la modificación de grupos políticos en el seno de las Corporaciones.

b) La regulación de los aspectos secundarios (tanto por lo que se refiere a la estructura, como por lo que respecta al funcionamiento) de los órganos necesarios, ciertamente en el marco de las disposiciones de la LRBRL y de la legislación autonómica de desarrollo de la misma.

c) La ordenación de los órganos complementarios (también bajo la doble perspectiva de la estructura y el funcionamiento) con el límite de las escasas determinaciones que en este punto realiza la LRBRL y de las que establezcan las Leyes autonómicas de desarrollo de ésta. Es justamente en este ámbito en el que se manifiestan, en toda su gravedad, las consecuencias negativas de la STC 214/1989, de 19 de diciembre, ya antes comentadas.

10 Conviene indicar que el Reglamento Orgánico, en cuanto decisión organizativa de importancia, precisa, para su aprobación o modificación, el voto favorable de la mayoría absoluta del número legal de miembros de la correspondiente Corporación. Consecuentemente, la opción por la inclusión en el mismo de una materia que no forme parte necesariamente del objeto del mismo conduce a una consecuente mayor rigidez en su regulación. 
Es de destacar que en este punto, al contrario que en el caso de los órganos necesarios, el Reglamento Orgánico puede desplegar la inventiva local en materia organizativa, creando órganos específicos (y regulando su funcionamiento) en función de las características y las necesidades de la correspondiente comunidad. La regulación (puramente supletoria) que de esta materia hace en su Título IV (arts. 119 y ss.) el Reglamento de Organización, Funcionamiento y Régimen Jurídico de las Entidades Locales, aprobado por Real Decreto 2568/1986, de 28 de noviembre, proporciona una buena idea de las posibilidades de configuración organizativa que aquí se le ofrecen a dichas entidades.

Debe considerarse, en todo caso, que la organización complementaria en la disposición de los entes locales cubre igualmente las decisiones de desconcentración que éstos pueden adoptar. Tales decisiones no tienen por qué circunscribirse, cuando menos en los Municipios, a la estructura administrativa central, pues el artículo 24 de la LRBRL autoriza expresamente órganos territoriales de gestión desconcentrada. Aunque la Ley no contiene parecida habilitación expresa para las Diputaciones (y, consecuentemente, para los Cabildos y Consejos insulares), en ausencia de precepto legal prohibitivo la capacidad de autoorganización de que gozan igualmente estos últimos entes obliga a entender que su potestad de autoorganización no es menor que la municipal (por más que, en razón de su misma naturaleza y función, la desconcentración juegue en la práctica un menor papel en este tipo de entes).

El citado artículo 24 LRBRL ilustra, por el argumento de maiore ad minus, sobre el doble carácter (sectorial y territorial) de la desconcentración en la disposición de los entes locales y también el contenido de las medidas desconcentradoras (pues éstas pueden y deben referirse, según el precepto legal, a la organización en sentido estricto, las funciones y las competencias). El Reglamento de Organización, Funcionamiento y Régimen Jurídico de las Entidades Locales, ya citado, contempla, en efecto, además de los que llama representantes del Alcalde (en poblados y barriadas separados del casco urbano y que no constituyan entidad local) y Juntas Municipales de Distrito -órganos éstos claramente encuadrables en la desconcentración territorial-, cualesquiera otros órganos desconcentrados que los Municipios puedan crear, sin otra limitación que el respeto a la legislación de régimen local (previsión que engloba indudablemente órganos de naturaleza sectorial). Pero lo más importante es, sin duda, la comprensión en la desconcentración de la manipulación del orden competencial orgánico interno de los entes locales, que resulta de la expresa autorización legal para la fijación de las competencias de los órganos desconcentrados de nueva creación (los territoriales y, por tanto y con mayor razón aún, los sectoriales). En la medida en que los entes locales no tienen 
otras competencias que las que les estén atribuidas legalmente, la asignación interna de competencias a estos últimos órganos ha de hacerse necesariamente a costa de los existentes, incluidos los de carácter necesario prefigurados - también en su dotación competencial- por la LRBRL, es decir, ha de suponer indefectiblemente una redistribución competencial en el seno de la correspondiente Administración. No puede ser de otra forma, so pena de condenar la desconcentración al plano de las funciones auxiliares de propuesta, sugerencia o informe; restricción, que en modo alguno se deduce del régimen local básico. La conclusión así alcanzada tiene una significación difícil de minusvalorar: la autoorganización local no opera sólo en la periferia de la estructuración de las correspondientes Administraciones; antes al contrario, es capaz de incidir en su mismo núcleo para producir la necesaria adaptación organizativa de las circunstancias peculiares de cada comunidad. Se trata ciertamente de una incidencia, en tanto que la capacidad de modulación de la estructura organizativa prefijada legalmente es limitada. Los límites son difíciles de determinar con carácter general, dado el relevante papel que en esta materia ha reconocido el Tribunal Constitucional a la legislación autonómica, pero es claro, en cualquier caso, que las medidas locales particulares no pueden legítimamente desnaturalizar la posesión y función que -en las respectivas estructuras administrativas- están reservadas constitucional y legalmente a los órganos superiores de carácter necesario. No otro es el sentido del inciso final del artículo 34 LRBRL, cuando prohíbe que la desconcentración lesione el principio de la unidad de gobierno y gestión del Municipio.

La desconcentración sectorial o, si se quiere, funcional, ofrece también muy amplias posibilidades a la iniciativa organizativa local, sobre todo si se pone en relación con la participación ciudadana (art. 69 LRBRL) y la promoción del asociacionismo de los particulares para la defensa de los intereses colectivos o «difusos» (art. 72 LRBRL). En el primer caso, los entes locales (cuando menos y desde luego todos los de carácter necesario) gozan de una habilitación genérica para definir las formas, los medios y los procedimientos de la participación, a ejercitar justamente en actuación de su potestad de autoorganización y sin otro límite que el no menoscabo de las facultades de decisión propias de los órganos representativos regulados por la Ley, es decir, del principio de autoadministración articulada sobre el principio de democracia representativa y no directa ${ }^{11}$. Por esta última razón (el límite legal

11 Con la excepción, naturalmente y en la instancia municipal, de los supuestos de autogobierno en régimen de Concejo abierto. Ocurre, sin embargo, que tales supuestos no constituyen propiamente una excepción, toda vez que en tales Concejos no hay necesidad de articulación de formas peculiares y complementarias de participación en la medida en que ésta es plena y se cumple a través del órgano máximo colegiado de la Corporación. 
a la técnica de la participación orgánica de los ciudadanos;, es claro que aquí no se dan los problemas de reasignación interna cle competencias a que puede dar lugar la opción desconcentradora. En el segundo caso, la promoción del asociacionismo ciudadano aparece expresamente conectada a la participación orgánica, en la medida en que el artículo 72 LRBRL mandata a los entes locales para que impulsen la intervención de las asociaciones en la gestión de la correspondiente Corporación, remitiendo a tal efecto al artículo 69. Nuevarmente aquí la previsión por el Reglamento de Organización, Funcionamiento y Régimen Jurídico de las Entidades Locales (arts. 130 y 131) de los que denomina «Consejos sectoriales» suministra un buen ejemplo de las posibilidades que, en este terreno, se ofrecen a las Corporaciones locales.

d) La regulación ${ }^{12}$, en detalle y de conformidad en todo caso con la legislación autonómica dictada en desarrollo del artículo 45 LRBRL ${ }^{13}$, de las entidades territoriales descentralizadas (de ámbito inframunicipal y referidas a núcleos de población separados del principal) ya existentes en el término municipal o que puedan crearse a iniciativa del propio ente local o de la población interesada ${ }^{14}$. Parece obvio que esta regulación puede comprender no sólo los aspectos puramente orgánicos, sino también los de funcionamiento y competenciales (suponiendo éstos, al igual que en el caso de la organización desconcentrada, una verdadera reasignación de competencias en el seno de la instancia municipal), así como los relativos a las relaciones con la entidad municipal.

Aunque por pertenecer más a la lógica y dinámica de la gestión de las actividades y los servicios ${ }^{15}$ no pueda decirse que el Reglamento

12 Esta posibilidad sólo existe para los Municipios, como es bien evidente.

13 Esta legislación ha de cumplir, a su vez, las reglas sustantivas que contiene el artículo 45 LRBRL.

14 La reserva por el artículo 45 LRBRL de la iniciativa para la creación de las entidades territoriales de ámbito inframunicipal indistintamente al Municipio y a la población interesada, significa que en este punto la potestad de autoorganización municipal se extiende tanto a la creación misma en el seno del Municipio de entidades territoriales descentralizadas (si bien aquí la potestad tiene —en principio y a reserva de lo que disponga la legislación autonómica一 una traducción concreta limitada, en cuanto que circunscrita al derecho de iniciativa, correspondiendo a la Comunidad Autónoma la decisión definitiva sobre la creación o no), como a la regulación de la organización de tales entidades (naturalmente en el marco de la legislación de régimen local, especialmente de la autonómica).

15 Por más que no por ello la descentralización funcional deje de ser materia estrictamente organizativa. Ocurre que las decisiones organizativas se toman en este terreno caso a caso y sin previa existencia de un esquema general, por más que éste sea posible $e$, incluso, conveniente (el inciso final del art. 133 del Reglamento de Organización, Funcionamiento y Régimen Jurídico de las Entidades Locales parece propiciar un tal esquema o, por lo menos, un planteamiento general, cuando sienta el principio de la economía organizativa y de consecuente reducción del número de entes descentralizados al menor posible). De hecho, la doble condición de este tipo de descentralización, de un lado componente importante del modelo estructural de la organización local y, de otro, instrumento para la adecuación de la forma de la organización a las características y las necesidades (cambiantes) de las concretas actividades y los específicos servicios ha determinado su inclusión por el citado Reglamento en la regulación general que realiza de la orga- 
Orgánico sea el lugar más idóneo para la toma de decisiones sobre el desarrollo de aquéllos por entes descentralizados, ni siquiera para las que puedan tener por objeto el despliegue de cometidos propios de la estructura administrativa directa a través de este tipo de entes ${ }^{16}$, nada obsta - antes al contrario, todo aboga en su favor ${ }^{17}$ - a que la expresa norma local contenga una ordenación general de los presupuestos, los requisitos y las condiciones para la toma de la decisión del establecimiento de entes funcionalmente descentralizados, así como para la elección entre una y otra clase de los mismos.

Huelga decir que la potestad de autoorganización no se agota en los contenidos posibles del Reglamento Orgánico. Se extiende desde luego a la determinación de la plantilla (relación de puestos de trabajo) y, consiguientemente, a la creación, definición, modificación y extinción de los puestos de trabajo reservados a funcionarios de carrera, los previstos para personal laboral y los atribuidos a personal eventual; decisión ésta que, por exigencia legal (art. 90.1 LRBRL), debe adoptarse en el contexto de la aprobación de los Presupuestos anuales. Esta descripción, motivada en razones de política de gestión de personal (poderosamente influida, a su vez, por razones de política de gestión económico-financiera), contribuye decisivamente al fenómeno de «degradación» de la organización administrativa a partir de los niveles profesionalizados que es observable en los últimos años ${ }^{18}$.

nización complementaria de las entidades locales, pero advirtiendo en el artículo 133 que el establecimiento de entes descentralizados funcionalmente se rige por lo dispuesto en la legislación de régimen local relativa a las formas de prestación de los servicios públicos.

16 Posibilidad, que es la que parece estar en la base de la previsión por el artículo $132 \mathrm{del}$ Reglamento de Organización, Funcionamiento y Régimen Jurídico de las Entidades Locales de la aplicación de la descentralización no sólo a «la actividad de prestación de los servicios», sino también a la consideración de ula necesidad de una mayor eficacia en la gestión, la complejidad de la misma (y) la agilización de los procedimientos».

17 Una regulación orgánica de la descentralización funcional, incluida la motivada en la prestación de los distintos servicios locales, introduciría un cierto orden en este terreno, al suponer la disciplina del correspondiente ente local en tal orden previo. Cabe dudar, sin embargo y cuando menos por lo que hace a la organización de los servicios, de la eficacia de tal disciplina, teniendo en cuenta la fuerza propia y la diversidad de la dinámica peculiar de cada uno de los servicios públicos locales.

18 La prescripción comentada en el texto trae causa del modelo básico impuesto por la Ley 30/1984, de 2 de agosto, sobre medidas para la reforma de la función pública, corregida luego parcialmente por la Ley 23/1988, de 28 de julio, derivada de la STC de 11 de junio de 1987. Quiere decirse, pues, que el problema aludido es general y no circunscrito a la Administración Local.

La política de personal ha incidido, así, en la organización administrativa, determinando que la estructura de ésta no se defina tanto en términos organizativos estrictos ( $y$, por tanto, conjuntamente con el resto de la organización actuada por no profesionales), cuanto de política de personal y conforme a una lógica propia. Esta circunstancia viene induciendo un proceso continuado de «separación» entre los dos expresados niveles organizativos (el de los órganos superiores, no cubiertos según la lógica de la política de personal y el de los que sí están sujetos a esta última), con la consecuencia de la generación y la consolidación progresiva de la idea de que esta última parte de la organización no integra verdaderos órganos administrativos capaces de ejercer, con efectos ad extra, una cierta medida de las competencias de la organización total correspon- 
Pero como es de todo punto lógico y no precisa justificación alguna cubre igualmente la actividad de organización, dirección y control de los procesos de información, elaboración, trabajo y decisión que se desarrollan en las estructuras locales en su funcionamiento dinámico; actividad, sin duda, comprendida en las expresiones «potestad de autoorganización de los servicios de la entidad local» (empleada por el art. 7.3 LRBRL para expresar el límite último a respetar en la atribución de competencias a los entes locales a título de delegación), «facultades de programación, planificación $u$ ordenación de los servicios o actividades de su competencia» (utilizada por el art. 59.1, párrafo tercero LRBRL para acotar el ámbito de autodisposición local en el marco de la coordinación articulada por una Administración mediante instrumentos de planificación sectorial) o "potestad de autoorganización de los servicios que corresponde a la entidad local» (reiterada por el art. 62, párrafo segundo LRBRL, para expresar el dominio indisponible para el legislador a la hora de articular las competencias en los supuestos complejos a que se refiere el precepto legal). Esta extensión de la potestad de autoorganización es obligada, en la medida en que es condición misma para la efectividad de la construcción de la Administración local sobre el principio de autonomía.

\section{LA AUTOORGANIZACION EN EL DOMINIO DE LAS ACTIVIDADES Y LOS SERVICIOS LOCALES; EL PROBLEMA ESENCIAL DE LA LIBERTAD DE ELECCION DE LAS FORMAS ORGANIZATIVAS}

Sin perjuicio de la posibilidad, ya comentada ${ }^{19}$, de la descentralización funcional de tareas y cometidos (generales) en principio propios de la Administración directa de los entes locales, la potencialidad creadora de nuevas organizaciones jurídicamente independientes (entes instrumentales) de la potestad de autoorganización local se mani-

diente. Las manifestaciones más visibles de tal idea son, de un lado, la concentración abrumadora de la toma de decisiones en los órganos superiores, y, de otro y por consecuencia, la reducción de los funcionarios a meros colaboradores del empresario «Administración", con pérdida de su condición de «parte» integrante (incluso «orgánica») de la propia Administración y, en tal calidad, ejercientes de «función pública», es decir, actuantes de las competencias atribuidas a la organización de la que forman parte. Desde la perspectiva que ofrece esta evolución, no es sorprendente, pues, el proceso de acercamiento entre el régimen de la función pública y el régimen del personal laboral, ni la laboralización de amplios segmentos de la Administración Pú. blica. En realidad, el régimen de la función pública ha dejado de ser la expresión de un status específico, cabalmente el adecuado a la situación de incorporación a la organización misma de la Administración y de participación, por tanto, en el ejercicio del poder público.

is Esta posibilidad sin duda existe, como ya se ha razonado. No obstante es menos clara que la ahora comentada en el texto, en la medida en que no se encuentra expresamente prevista -a diferencia de ésta - en la legislación básica de régimen local y carece, por tanto, de los nítidos perfiles que la conferida para optar entre diversas formas de organización de los servicios. 
fiesta primordialmente en el ámbito acotado por la LRBRL con la expresión «actividades y servicios», definido luego de forma más estricta por los artículos 85.1 y 86 de dicho texto legal en los siguientes términos: servicios son todos aquellos que tiendan a la consecución de los fines señalados como de la competencia de las entidades locales ${ }^{20}$ y por actividades deben entenderse aquellas que supongan ejercicio de la iniciativa pública en la economía conforme al artículo $128 \mathrm{CE}$ (tanto las que se cumplan en régimen de monopolio, como las que lo hagan en régimen de libre concurrencia).

El artículo 85.2 LRBRL autoriza a los entes locales a optar para la organización de la prestación de sus servicios entre un conjunto amplio y variado de formas, agrupadas en las dos categorías de gestión directa e indirecta y con la prohibición de elegir las de la segunda para servicios que impliquen ejercicio de autoridad ${ }^{21}$. En la posibilidad de la llamada a la colaboración de la iniciativa privada para la gestión de servicios públicos (en la incorporación de particulares a la propia organización o, si se quiere, la utilización de los mismos como piezas de ésta con un status peculiar no hay, obviamente, novedad alguna) ${ }^{22}$. El interés principal lo presenta la amplitud con que se reconoce la capacidad «fundacional» de entes instrumentales, tanto de Derecho público (Organismos Autónomos), como de Derecho privado (sociedades mercantiles), dentro de la categoría de la gestión directa. No es de este lugar el estudio de las distintas formas de organización de que puede hacer uso, en este capítulo, la potestad de autoorganización ${ }^{23}$, por lo que baste con destacar que ésta se extiende válidamente a la elección de la forma tanto de la prestación, como de la organización y, a este último respecto, comprende la definición de la estructura, el Derecho a que se sujeta, en su caso, la acción del ente ${ }^{24}$, los medios materiales,

20 La definición es de gran amplitud, pues a tenor del artículo 25.1 LRBRL los Municipios pueden (en el ámbito de su competencia) promover toda clase de actividades y prestar cuantos servicios públicos contribuyan a satisfacer las necesidades y aspiraciones de la comunidad vecinal; y, conforme a los artículos 31.2 y 36.1 de la misma Ley, las Diputaciones tienen como fin propio, entre otros y en particular, el de asegurar la prestación integral y adecuada en la totalidad del territorio provincial de los servicios de competencia municipal, alcanzando su competencia a cuanto, en general, sea subsumible en el fomento y la administración de los intereses peculiares de la Provincia.

21 Esta prohibición no es excesivamente constrictiva, si se tiene en cuenta el elenco de formas de gestión que comprende la categoría de gestión directa y la inclusión en el mismo de las sociedades mercantiles cuyo capital pertenezca íntegramente a la correspondiente Entidad Local.

22 Más novedosa es la lista de formas en la gestión indirecta, en tanto que tiende a «normalizar» la capacidad organizativa de los entes locales, extendiéndola a formas utilizadas por la Administración del Estado.

${ }^{23}$ A este respecto véase el reciente y excelente estudio de F. SOSA WAGNER: La gestión de los servicios públicos locales, Ed. Civitas, Madrid, 1992.

24 El articulo 145.2 de la Ley 39/1988, de 23 de diciembre, de Haciendas Locales, los Organismos Autónomos de las Entidades Locales se clasifican en Organismos Autónomos de carácter administrativo y Organismos Autónomos de carácter comercial, industrial, financiero o análogo. La clasificación lo es ciertamente a los efectos del régimen presupuestario y contable, pero resulta obvio que trasciende también al régimen de su actividad. 
económico-financieros ${ }^{25}$ y personales, así como la determinación del fin, el objeto, la competencia y el funcionamiento del mismo. Dado que la legislación básica de régimen local no contempla control de legalidad alguno sobre los actos organizativos locales de establecimiento de entes instrumentales propios (en forma jurídico-pública o jurídicoprivada) ${ }^{26}$, desde la doctrina del Tribunal Constitucional y también hoy del Tribunal Supremo ${ }^{27}$ deben considerarse derogadas todas las

25 Conforme a los artículos 112.1 LRBRL y 145.1 de la Ley 39/1988, de 23 de diciembre, de Haciendas Locales, el presupuesto anual de las Entidades Locales es único y en él han de integrarse los presupuestos de los Organismos Autónomos y los estados de previsión de gastos e ingresos de las sociedades mercantiles cuyo capital social pertenezca íntegramente a la Entidad Local.

26 El fundamento no es otro que el carácter nuclear de la potestad de autoorganización respecto de la autonomía local y el agotamiento de las disposiciones organizativas consideradas en la esfera del interés de la correspondiente comunidad.

27 En este sentido, ya tempranamente, la STC 4/1981, de 2 de febrero, y luego las SSTC de 29 de abril de 1981, 28 de junio de 1983, 5 de diciembre de 1984 y 27 de febrero de 1987. El cuerpo de doctrina establecido por estas Sentencias (recordado luego por la STC 170/1989, de 19 de octubre, y precisado por la STC 148/1991, de 4 de julio) puede resurmise así:

- Los controles administrativos concretos no vulneran el núcleo esencial de la garantía institucional de la autonomía local (cuando ésta se concreta en competencias propias plenas), lo que sí sucede, por contra, con los controles genéricos e indeterminados que sitúan a los entes locales en una posición de subordinación o dependencia cuasi jerárquica de la Administración del Estado o de otras entidades territoriales.

- El fundamento del control legítimo constitucionalmente no es otro que el principio de unidad, en relación con la supremacía de los intereses de las comunidades territoriales más amplias sobre los de las comunidades más reducidas.

- En todo caso, el control de legalidad ha de ser concreto y articulado como mecanismo de impedimento de la incidencia en intereses supralocales. Especialmente por lo que hace a la técnica de la suspensión gubernativa, como manifestación del control de legalidad, no es compatible con la autonomía local cuando se utiliza exclusivamente para la preservación de la estricta legalidad, pero sí lo es cuando se emplea para defender la competencia propia de la Administración superior, corregir invasiones de ámbitos ajenos a la competencia local o subsanar afecciones a materias entregadas a otras Administraciones.

Por lo que hace al control de oportunidad, en ningún caso puede abocar en una compartición en la toma de las decisiones que deban corresponder a las entidades locales, salvo las excepciones que puedan encontrar un expreso fundamento constitucional.

Con referencia a la técnica de control subjetivo sobre los órganos locales (suspesión o destitución de cargos), resulta incompatible con la autonomía local cuando se funda en la gestión inadecuada de los intereses propiamente locales, pero no así, sin embargo, cuando sirve a la defensa de intereses supralocales.

- Las competencias locales atribuidas a título de delegación, así como (las de gestión y ejecución) las compartidas con otras Administraciones no están automáticamente sujetas por las reglas anteriores, pudiendo tener un régimen específico de ejercicio (por lo que hace a los controles) en función de sus características concretas. En esta materia la jurisprudencia del Tribunal Supremo ha ido evolucionando, produciendo ciertamente pronunciamientos contradictorios y, en algunos casos, criticables, pero teniendo perfectamente claros los criterios correctos y a la vista y presente, en todo caso, la doctrina del Tribunal Constitucional.

Las primeras sentencias se enfrentan con la cuestión de la pervivencia de determinados mecanismos de control gubernativo en materia urbanística (concretamente el previsto en el art. 186 de la Ley del Suelo). Inicialmente y desde la consideración de que el urbanismo supone compe tencias concurrentes municipales y de otras instancias, el Tribunal Supremo afirma la supervivencia del aludido mecanismo, considerando que es posible considerarlo como uno de los controles compatibles con la autonomía local en los términos de la doctrina del Tribunal Constitucional: SS de 30 de mayo, 17 de octubre y 20 de diciembre de 1984, 30 de octubre de 1985 
técnicas de aprobación y, en general, de control previstas en este ámbito por la legislación sectorial. Así sucede, significativamente, con la aprobación definitiva de la creación y los Estatutos de Gerencias urbanísticas municipales o provinciales, la determinación de las facultades del Gerente y del régimen de recursos contra sus actos y la designación del propio Gerente, atribuidos por el artículo 18 del Reglamento de Gestión Urbanística, aprobado por Real Decreto 3288/1978, de 25 de agosto, a la Administración del Estado y que corresponderían hoy, por tanto, a la Administración de la respectiva Comunidad Autónoma.

(vol. II de la obra citada en la nota 1, respectivamente pp. y Cdos.: 142 y ss., 7."; 195 y ss., 2."; 212 y ss., $2 .^{\circ}$, y 331 y ss., 3.\%). La Sentencia de 21 de febrero de 1985 (vol. II de la obra citada en la nota 1, pp. 413 y ss., Cdo. 3.\%), estimando que la Ley 40/1981 introdujo una protección más rígida de la autonomía local, declara, sin embargo, derogado el artículo 186 de la Ley del Suelo. La Sentencia de 5 de noviembre de 1986 (vol. II de la obra citada en la nota 1, pp. 604 y ss., Cdo. 3.9) afronta la contradicción introducida en la jurisprudencia por el pronunciamiento anterior, inclinándose por la no derogación del precepto legal al entender que es preciso agotar las posibilidades de una interpretación conforme a la Constitución. Esta línea se mantiene (SSTS de 24 de abril de 1987 y 27 de mayo de 1988 y Auto de 2 de julio de 1988; vol. III de la obra citada en la nota 1 , respectivamente pp. 321 y ss., 764 y ss., y 827 y ss.; Cdos. $4 .^{\circ}, 2 .^{\circ}$ y $30^{\circ}$ y $6 .^{\circ}$; también respectivamente $\operatorname{Ar}, 4758,4512$ y 5846) hasta la STC 213/1988, de 11 de noviembre, sobre constitucionalidad de determinada normativa urbanística catalana. La jurisprudencia del Tribunal Supremo se adecua inmediatamente a la doctrina sentada por el Tribunal Constitucional y comienza ya, definitivamente, a declarar derogado el artículo 186 de la Ley del Suelo por contravenir el modelo único de relaciones de los entes locales con los poderes territoriales superiores diseñado en el régimen local básico: Autos del TS de 27 de diciembre de 1988 y 3 de julio y 24 de noviembre de 1989, Ar. 10245, 5575 y 8321 , Cdos. $2 .^{\circ}, 3 .^{\circ}, 4 .^{\circ}$ y $5 . \circ ; 1 . \circ$, y $1.0^{\circ}$, respectivamente.

Doctrina general sienta la STS de 10 de noviembre de 1988 (Ar. 8919, Cdo. 1.०), señalando que la autonomía local modifica sustancialmente el ámbito de las potestades de fiscalización de las instancias superiores sobre los actos de los entes locales, si bien no excluye de modo absoluto cualquier control gubernativo de legalidad, al menos cuando los actos locales afecten directamente las competencias de las Administraciones superiores o extravasen de la esfera de actuación propia de los entes lcoales. Invoca expresamente la doctrina de las SSTC de 2 de febrero y 29 de abril de 1981 .

Es de destacar que las SSTS de 27 de julio de 1987 y 6 de febrero de 1988 (Ar. 7686 y 783; Cdos. $5 .^{\circ}$ y $3 .^{\circ}$, respectivamente) distinguen perfecta y correctamente, en materia urbanística y dada la no pertenencia de ésta a la entera competencia municipal (concurriendo también competencia autonómica), la aprobación definitiva del planeamiento urbanístico de las técnicas de control sobre los entes locales. Dicha aprobación no supone un control, sino el ejercicio de una competencia autonómica propia, concurrente con la local, agotándose esta última en la aprobación provisional, toda vez que en este acto cristaliza ya la voluntad municipal en cuanto al modelo territorial elegido como marco de convivencia en el territorio de la jurisdicción local. En la misma línea se sitúan las SSTS de 14 de marzo, 29 de abril y 27 de julio de 1988 (Ar. 2164, 3292 y 6339 ; Cdos. $6 .^{\circ}, 2 .^{\circ}$ y $3 .^{\circ}$, respectivamente).

En el mismo sentido, aunque con relación a la intervención antes estatal y ahora autonómica prevista en el artículo 43.3 de la Ley del Suelo de 1976, la STS de 15 de noviembre de 1988 (Ar. 9086, Cdo. 4..$^{\circ}$ sostiene, con criterio acertado, que aquella no expresa control alguno contrario a la autonomía local y sí más bien la incidencia en la cuestión de intereses urbanísticos supralocales.

Por su parte la STS de 30 de diciembre de 1988 (Ar. 10263, Cdo. 3.०) establece, con cita de Sentencias anteriores, que la aprobación autonómica de los Estatutos de una Mancomunidad de Municipios es una técnica de control compatible con la autonomía municipal. 
La actuación de la iniciativa local para el ejercicio de actividades económicas conforme a la habilitación general contenida en el artículo $128 \mathrm{CE}$, tiene también, obviamente, contenido organizativo. Por de pronto, la opción entre el desarrollo de la actividad en régimen de libre concurrencia o de monopolio trasciende a la configuración interna misma de la esfera de competencia de la Entidad Local y, asimismo, a la división, en el territorio de ésta, entre los campos de las actividades en la disposición de todos los sujetos de derecho y las reservadas a la Administración Pública ${ }^{28}$. En cualquiera de los dos supuestos el contenido de la decisión organizativa es equiparable al propio de las referidas a los servicios públicos ${ }^{29}$, si bien en la hipótesis de gestión directa de la actividad no parece plausible, en cualquier caso, la utilización de las formas organizativas consistentes en la gestión indiferenciada por el propio aparato administrativo local y en el Organismo Autónomo de carácter administrativo.

El principal problema dogmático que ofrece la potestad de organización en el dominio tanto de los servicios, como de las actividades de contenido económico es el de su ámbito legítimo o, lo que es igual, el de la capacidad para crear nuevas organizaciones, dotadas o no, a su vez, de capacidad jurídica plena, fundamentalmente en el plano del Derecho privado. La cuestión excede desde luego del régimen local, por ser común a todas las Administraciones Públicas, pero su actualidad entre nosotros ${ }^{30}$ justifica sobradamente que la abordemos en este

28 La competencia a este respecto de las entidades locales es, en cualquier caso, imperfecta, toda vez que sus decisiones precisan de la aprobación del órgano de gobierno de la correspondiente Comunidad Autónoma, según determina el último párrafo del artículo 86 LRBRL.

29 El núm. 2 del artículo 86 LRBRL precisa, para el caso de actividades a realizar en régimen de libre concurrencia, que la decisión del Pleno de la Corporación ha de fijar, además, la forma concreta de gestión del servicio. Aunque la expresión empleada no es feliz, pretende indicar con toda claridad la necesidad de optar expresamente por una gestión directa o indirecta de la actividad y también por una forma organizativa precisa.

30 Esa actualidad trae causa de la confusión reinante en el terreno de la organización administrativa en cuanto a las formas y la capacidad jurídico-pública o jurídico-privada de las mismas. La confusión proviene del favorecimiento decidido e, incluso, el franco abuso en los últimos años de las formas jurídico-privadas de organización, desde una utilización despreocupada y puramente instrumental de las mismas y, en todo caso, desprovista de toda referencia en un esquema general ordenador, sobre la base del predominio de la perspectiva propia de la política económica y, por tanto, de la lógica y las técnicas de la gestión «privada» o empresarial, inspiradas en la eficiencia. La confusión ha llegado a tal punto que, en recientes y muy controvertidas actuaciones del sector público (como las que, realizadas por RENFE y una empresa filial de la misma en los Municipios de Alcobendas y San Sebastián de los Reyes, han desencadenado, incluso, procesos judiciales e investigaciones parlamentarias), los interrogantes principales (de dificil respuesta) residen, en lo que ahora interesa, en la legitimidad o no, a pesar de la capacidad jurídico-privada de las organizaciones de que se trata, de determinados actos, realizados en los mismos términos que si se hubiera tratado de sujetos ordinarios de derecho. El proceso ha podido desarrollarse de forma espectacular sin que en la doctrina se haya suscitado una reflexión o preocupación o un debate mínimente significativos, en razón tanto del abandono por ésta en los últimos tiempos de las cuestiones organizativas, como a la vigencia indiscutida (por práctica inexistencia de toda crítica) del principio de básica libertad de elección por la Administración de las formas de organización de sus tareas, actividades y servicios. El carácter «doméstico" de la potestad de organización ofrece a este respecto un apoyo decisivo. 
contexto, siquiera sea para aludir muy esquemáticamente a sus aspectos esenciales. Involucra, en efecto, asuntos de tanto calado dogmático como la división entre Derecho público y Derecho privado, la distinción entre sociedad y Estado y la diferenciación entre capacidad jurídica y de obrar de Derecho privado y de Derecho público ${ }^{31}$. En lo que aquí importa, si bien cabe continuar manteniendo el principio de la básica libertad de la Administración para elegir, de entre las admitidas en Derecho, la forma de organización más conveniente a la actividad o al servicio de que se trate $y$, por tanto, para efectuar la doble opción entre formas jurídico-públicas y jurídico-privadas y sujeción de la acción al Derecho público o al Derecho privado, resulta preciso afirmar inmediatamente que dicha libertad no supone en modo alguno una ilimitada facultad para dotar a las organizaciones creadas de una capacidad jurídica y de obrar plenas, en el sentido de equiparables a las que son propias de los sujetos ordinarios y primarios del Derecho, es decir, de las personas físicas. Esto es así por la diferencia de naturaleza que existe entre las personas jurídico-públicas y las jurídico-privadas reconducibles en último término a las físicas (por dimanar de, servir a o ser instrumentos de éstas). Mientras las personas físicas (y, por extensión, las jurídicas por ellas creadas) son sujetos dotados de capacidad plena, en tanto que «colocadas» en el mundo del Derecho y dotadas de autonomía de la voluntad (como correlato a la libertad que les está constitucionalmente asegurada como posición de base), con la consecuencia de su ideoneidad para ser potenciales destinatarias de todas las normas y, por tanto, de ser titular de cualesquiera derechos y obligaciones (modelo este sobre el que está construida la categoría de la capacidad jurídica y de obrar en el Derecho civil y mercantil, que es plena o sin restricciones), no sucede lo mismo con las personas jurídico-públicas, cuya construcción está basada en el principio de legalidad y, por ello, de la potestad-competencia (modelo este jurídico-público, al que responde una capacidad jurídica y de obrar distinta de la anterior; distinta, justamente por ser inmanente a la misma límites precisos). Las personas jurídico-públicas no responden a la idea del libre desarrollo de la personalidad (individual o asociadamente), sino a la de servicio de la legalidad en un ámbito perfecta y jurídicamente acotado. De ello se deduce que, si las personas jurídico-privadas en sentido estricto tienen de ordinario capacidad jurídica y de obrar

31 Todas estas cuestiones han sido abordadas recientemente, justamente desde la perspectiva de la supuesta libertad de elección de la Administración Pública en punto a formas de or. ganización, por B. KEMPEN, en el trabajo de Dissertation presentado a la Facultad de Derecho de Colonia en 1988 y publicado en 1989 con el título Die Formenwablfreibeit der Verwaltung. Die öffentliche Vervaltung zwischen öffentlichem und privatem Recht, Ed. Verlag Franz Vahlen, Múnich, 1989. El estudio pone en tela de juicio las ideas establecidas y aceptadas comúnmente en este crucial tema. 
plena, las personas jurídico-públicas únicamente cuentan con una capacidad parcial, cabalmente la que esté prefigurada por el conjunto de habilitaciones-mandatos de actuación de que sea destinataria. Alcanzada esta conclusión, de ella misma deriva con toda naturalidad la de la imposibilidad del surgimiento, del ejercicio de la potestad de autoorganización de una Administración, de una nueva organización - sea con forma jurídico-pública, sea con forma jurídico-privada, y con independencia del Derecho, público o privado, a que se someta su actividad - con una capacidad jurídica y de obrar más amplia que la poseída por la propia Administración matriz o de origen. De donde se deduce que todas las organizaciones instrumentales creadas por una Administración territorial (también, pues, las entidades locales) e, incluso, todas las organizaciones privadas (también las sociedades mercantiles con objeto económico a perseguir en régimen de libre concurrencia) fundadas por aquélla o por entes dependientes de la misma tienen sólo una capacidad jurídica y de obrar parcial o limitada, circunscrita y vertebrada, en todo caso, por el giro o tráfico (jurídico-público) de la organización creadora.

\section{LA AUTOORGANIZACION EN EL AMBITO DE LAS RELACIONES INTERADMINISTRATIVAS}

Hasta aquí hemos contemplado la autoorganización local desde la hipótesis ordinaria y clásica de la exacta correspondencia entre esfera administrativa (presidida por una Administración territorial) y ámbito de competencias, sobre la base del esquema conceptual articulado sobre el supuesto principal de la competencia como habilitación-deber completo, perfectamente definido y acotado (y, por ello, separado claramente de los restantes) y, consecuentemente, susceptible de ser actuado-cumplido por la esfera administrativa destinataria-titular de modo autosuficiente. Sin embargo, el carácter «compuesto» del Estado constituido en 1978 y el pluralismo territorial administrativo y competencial que de él resulta, obligan a un profundo replanteamiento de la hipótesis y del esquema aludidos. Pues en tal Estado - y éste es uno de los principales y más agudos problemas del Estado autonómico, en su fase actual, que puede considerarse ya iniciada, de funcionamiento «normal»- son absolutamente usuales los fenómenos de competencias «relacionadas» o «conectadas» por razón de compartición, concurrencia o complementariedad e, incluso, de «confluencia», «conjunción» o «suma» de competencias separadas o independientes; extremo éste, en el que, por conocido, no es preciso insistir. La LRBRL se hace eco de la «normalidad» de tales fenómenos en el Capítulo II, «Rela- 
ciones interadministrativas», de su Título V, «Disposiciones comunes a las entidades locales».

Es sabido también que la descentralización territorial interna del poder público no implica - como resulta de la consagración directa por la Constitución de un único orden material último, básico o fundamental, condicionante del ejercicio de cualesquiera de los poderes constituidos - la renuncia total a la unidad como principio y estado sustantivos, si bien la articulación de aquella descentralización sobre la autonomía impide que la efectividad y la consecución de éstos se alcancen sobre la base de técnicas tradicionales de jerarquización o cuasi jerarquización entre las distintas instancias territoriales de poder ${ }^{32}$. La unidad, que en el ámbito administrativo se traduce en un eficaz servicio a los intereses generales, es decir y en último término, la correcta realización del orden constitucional (art. 103.1 CE), presupone la pluralidad de instancias de decisión, autónomas entre sí; en el plano administrativo, la diversidad de las Administraciones públicas, gestoras de círculos de intereses determinados por distintas colectividades o comunidades territoriales y ejercientes de elencos de competencias construidas en función de tal gestión.

Así, pues, la reducción a unidad del complejo escenario administrativo sólo en medida muy parcial e, incluso, deficiente puede conseguirse a través de mecanismos que, aun suponiendo la relación entre las Administraciones, preserven su funcionamiento separado, con mantenimiento de los principios de la irrenunciabilidad de la competencia y actuación de ésta de forma independiente por unidades, establecimientos u organizaciones articulados y dirigidos con arreglo a la propia potestad de autoorganización (aun siendo desde luego indispensables los mecanismos de este carácter). En la construcción de tales mecanismos sólo caben dos grandes alternativas, según que la solución se fíe o no al conflicto formalizado como tal. Ejemplos de este tipo de solución en la LRBRL, en sus dos variantes básicas expuestas, son los siguientes:

A) Mecanismos sin necesidad de conflicto formalizado:

a) La creación por las instancias territoriales superiores competentes de órganos colegiados, de carácter deliberante y consultivo, para la coordinación interadministrativa (art. 58.1). Aquí la coordinación no enerva — dada la limitación funcional de los órganos a su servicio- la

32 No se trata de negar la legitimidad constitucional de la previsión, dentro de ciertos márgenes y al menos por lo que respecta a la autonomía local, de técnicas de control y de tutela gubernativas o administrativas. Más sencillamente, se pretende llamar la atención únicamente sobre el hecho de que las referidas técnicas han dejado ya de constituir el entero soporte de la unidad del sistema estatal en su conjunto y también e incluso el núcleo principal de los mecanismos idóneos para inducir y mantener tal unidad. 
actuación independiente de cada Administración conforme a su lógica propia.

b) El ortorgamiento a una Administración superior de la capacidad para la fijación de un marco a la actividad de la Administración local (art. 59). En este caso, el plan sectorial definido por aquella presupone justamente el respeto de un espacio propio a ésta; espacio, en el que la Administración local despliega su potestad de autoorganización, como expresamente se encarga de recordar el último párrafo del número 1 del citado artículo 59.

c) La sustitución de la Administración local por la Administración superior en caso de inactividad de la primera (art. 60). Tampoco hay aquí alteración del cuadro legal competencial y sí tan sólo ejecución material de la actividad omitida a costa de la Administración local.

B) Mecanismos que pueden desembocar o desembocan en conflicto o que operan sobre la base de éste:

a) Suspensión de acuerdos y adopción de las medidas pertinentes en caso de atentado grave al interés general de España, con impugnación de aquellos ante la Jurisdicción contencioso-administrativa (art. 67).

b) Disolución de los órganos de las Corporaciones locales en caso de gestión gravemente dañosa para los intereses generales constitutiva de incumplimiento de obligaciones constitucionales (art. 61).

c) Requerimiento potestativo e impugnación jurisdiccional de los actos y acuerdos locales que infrinjan el ordenamiento jurídico correspondiente a cada una de las Administraciones superiores (art. 65).

d) Impugnación jurisdiccional de los acuerdos locales que menoscaben las competencias de las Administraciones superiores, interfieran su ejercicio o excedan de la competencia de la entidad correspondiente (art. 66).

El elenco de los anteriores mecanismos puede completarse con fórmulas más o menos intermedias, como la prevista en el artículo 62 LRBRL para los supuestos de imbricación de los intereses gestionados por diferentes Administraciones, en los que resulte muy difícil una asignación diferenciada limpia de competencias a éstas ${ }^{33}$, pero lo que merece ser destacado es el hecho de que tales mecanismos no sólo no agotan el sistemas de relaciones interadministrativas, sino que ni siquiera integran el cuerpo de los primariamente llamados a asegurar un fun-

33 Como ha destacado la STC 214/1989, de 21 de diciembre, el artículo 62 LRBRL debe considerarse que forma parte del sistema legal de atribuciōn de competencias a los entes locales. Con ello, queda claro que si bien en los supuestos considerados por el precepto legal los procedimientos de toma de decisiones involucran a dos o más Administraciones, ello no significa confusión en las competencias de éstas. 
cionamiento coherente de las Administraciones públicas involucradas en cada caso. Como resulta tanto de los principios generales consagrados en el artículo 55 LRBRL, como de lo dispuesto en el artículo 57 en relación con los artículos 58 y $59^{34}$ y, por supuesto, de la propia lógica de las técnicas articuladas en los restantes preceptos legales antes examinados, la interacción de la Administración local con cualquiera de las Admnistraciones superiores reposa básicamente sobre la cooperación y la colaboración voluntarias, a cuyo servicio coloca la LRBRL (art. 58), en todo caso y sin perjuicio de cualesquiera otras previsiones legales, el consorcio y el convenio, es decir y en definitiva, el acuerdo interadministrativo. F. LLISET BORRELL ${ }^{35}$, tomando pie en la comprobación de que el pluralismo territorial derivado de la autonomía supone con normalidad _en aras de la coherencia de la actuación de las Administraciones públicas - la necesidad de la modulación del ejercicio por éstas de sus competencias propias, ha llamado recientemente la atención sobre la importancia de la técnica convencional interadministrativa y la procedencia de su ubicación, a este respecto, en la teoría de la organización. La consecución de determinados intereses generales (sustantivamente hablando), tal como éstos se encuentran prefigurados por el orden constitucional, puede requerir, en efecto y desde luego cuando en el cuadro competencial luce la concurrencia, la compartición o la complementariedad, la acción combinada o conjunta de la Administración local y otra o de las dos restantes Administraciones territoriales superiores; acción ésta que, conforme a lo dicho, debe articularse en primera instancia y preferentemente sobre el acuerdo voluntario.

La conclusión alcanzada significa que dicho acuerdo puede tener por objeto lícito las condiciones y los términos de la actuación de las competencias correspondientes a las diferentes Administraciones, con consecuencias, por tanto y en su caso, sobre la organización de los medios de cada una éstas puestos al servicio del ejercicio de las aludidas competencias. Así pues, y en lo que aquí interesa, la potestad de autoorganización de los entes locales está en juego no sólo cuando se trata de la articulación y la dirección de los medios propios para el desarrollo independiente de las propias competencias, sino también cuando dicho desarrollo se realiza junto y en unión con el de otras competencias de otras Administraciones, es decir, en el marco de relaciones interadministrativas.

34 El inciso inicial de este precepto es absolutamente concluyente, cuando determina que la entrada en juego del mecanismo en el previsto es subsidiaria respecto de la de los contemplados en los artículos inmediatamente anteriores.

35 F. LLISET BORRELL: «Los convenios interadministrativos de los entes locales», REDA, núm. 67, pp. 389 y ss. 
En la LRBRL es claro que el acuerdo interadministrativo puede afectar el orden competencial, flexibilizando, así, el principio de irrenunciabilidad y, por tanto, de indisponibilidad de la propia competencia sentado en el artículo 4 de la vigente Ley de Procedimiento Administrativo ${ }^{36}$. Basta, para justificar la anterior afirmación, con la simple enumeración de las previsiones que al respecto contiene el texto legal: el artículo 26 refiere la prestación de los servicios municipales mínimos al doble supuesto de la acción municipal independiente y la realizada en asociación (sin limitación de la forma de ésta), el artículo 27 contempla las delegaciones intersubjetivas de Administraciones superiores en los Municipios, el artículo 36.2.b) remite para la asistencia y la cooperación de las Diputaciones en los servicios municipales a cualesquiera de las fórmulas admitidas legalmente, el artículo 44 regula las Mancomunidades como asociaciones municipales voluntarias, el artículo 47.3 alude tanto a la posibilidad para los Municipios de crear organizaciones asociativas distintas a las Mancomunidades [apartado b)], como a su capacidad para transferir a otras Administraciones funciones y actividades [apartado $c$ )] y el artículo 87 aclara que los consorcios constituidos por los entes locales pueden tener por objeto la consecución de fines de interés común.

De esta suerte y siguiendo la clasificación establecida por F. LLISET BORRELL ${ }^{37}$, los acuerdos interadministrativos que suscriban los entes locales pueden ser no sólo puramente obligacionales, con efectos únicamente entre las partes y sin trascendencia - necesariamente- en el plano organizativo y competencial, es decir, caracterizables genéricamente como convenios-contratos. Caben también los convenios que tengan por objeto:

a) La transferencia de competencias o el condicionamiento o la modulación del ejercicio de éstas. La manipulación del régimen competencial puede tener lugar aquí con o sin creación de una nueva organización (con personalidad distinta de la de las Administraciones firmantes). La trascendencia organizativa del convenio dependerá normalmente de su objeto, según se refiera éste a funciones públicas que, a tenor de la legislación de régimen local, deban gestionarse de forma directa; el apoyo de otra Administración al cumplimiento por la municipal de sus obligaciones legales (asistencia y cooperación técnica, económica y jurídica); el ejercicio común de competencias paralelas, compartidas o complementarias; o la realización, asimismo en común, de obras y servicios (mancomunación o asociación de servicios municipales; consorcio de servicios públicos; gestión directa o indirecta en

36 En este sentido, F. LliSET BORRELl, op. cit., en nota anterior, p. 393.

37 Op. cit., en nota 35. 
común, mediante el empleo de cualquiera de las formas previstas en la legislación de régimen local).

b) La creación, directamente, de nuevas organizaciones públicas (Mancomunidades, Consorcios), formas personalizadas para la gestión de servicios públicos (sociedades mixtas) o empresas para la realización de actividades de contenido económico.

Todos estos supuestos tienen en común el ejercicio de la potestad de autoorganización de los entes locales para la creación de una nueva situación en la que, por alteración del sistema de competencias o del ejercicio de éstas o por el establecimiento de nuevas organizaciones, dichos entes locales pierden la plena disposición para la rearticulación del objeto del convenio celebrado mediante un nuevo ejercicio unilateral de la aludida potestad. Nada puede obstar a ello, si se tiene en cuenta que esta limitación es resultado de un previo ejercicio, bajo la propia responsabilidad y, por tanto, en régimen de autonomía, de la potestad de autoorganización, con la consecuencia de una vinculación por acto propio voluntario.

Las posibilidades de disposición sobre la organización y las competencias propias que se abren, así, en virtud de la técnica del convenio ${ }^{38}$, suscitan numerosos interrogantes aún no debidamente resueltos en nuestro ordenamiento jurídico, entre los que cabe destacar en lo que ahora importa, además de todos los relativos al contenido y alcance legítimos, la celebración, efectos, cumplimiento y ejecución (incluidos los contenciosos a que ésta dé lugar) de los convenios, el atinente justamente a la incidencia de éstos en la comparecencia y en la organización, dando lugar a verdaderas Administraciones mixtas, que desvirtúan o, en todo caso, pueden llegar a desvirtuar el modelo de Estado compuesto - basado en la autonomía y, por tanto, en la básica separación de las esferas administrativas-, con repercusión desde luego en los ciudadanos y las relaciones de éstos con las Administraciones públicas. No es, sin embargo, de este lugar el estudio de estos problemas. Baste aquí con llamar la atención sobre su existencia y la necesidad de afrontarlos y darles una satisfactoria solución, si se quiere que las potencialidades que encierran los nuevos mecanismos no queden cegadas desde un principio por deficiencias inevitables en su aplicación práctica.

38 Es de notar que el proyecto de ley sobre el régimen jurídico básico de las Administraciones públicas (así como procedimiento administrativo común y responsabilidad patrimonial) recientemente aprobado por el Gobierno de la Nación asume la técnica del convenio administrativo, incluso dando lugar a consorcios, en el sistema general de relaciones interadministrativas que diseña, generalizando, así, las previsiones de la legislación básica de régimen local. 
DA-1991, núm. 228. LUCIANO PAREJO ALFONSO. La potestad de autoorganización de la Administr...

DA-1991, núm. 228. LUCIANO PAREJO ALFONSO. La potestad de autoorganización de la Administr... 